\title{
Exploration of Teaching and Education: Integration of Sports and Medicine in Physical Education in Colleges and Universities
}

\author{
Yuhan Chao ${ }^{*}$, Xiucheng Guo², Rui Wang3 \\ ${ }^{1}$ Taishan University, Tai'an 271000, Shandong Province, China \\ ${ }^{2}$ The Second Affiliated Hospital of Shandong First Medical University, Tai'an 271000, Shandong Province, China \\ ${ }^{3}$ Shandong First Medical University, Tai'an 271000, Shandong Province, China
}

*Corresponding author: Yuhan Chao, yohanna@vip.163.com

Copyright: (C) 2022 Author(s). This is an open-access article distributed under the terms of the Creative Commons Attribution License (CC BY 4.0), permitting distribution and reproduction in any medium, provided the original work is cited.

\begin{abstract}
Based on the concept and definition of "integration of sports and medicine," this paper analyzes the current situation of the integration, where it lacks innovative physical education curriculum content and physical education teachers with conventional medical professional knowledge; in addition, physical education disciplines with medical characteristics are not highlighted. Therefore, relevant measures are put forward for reference and discussion.
\end{abstract}

Keywords: School of physical education; Integration of sports and medicine; Education and teaching strategy

Online publication: January 20, 2022

\section{Introduction}

The integration of sports and medicine has become a hot topic in the field of sports medicine. The integration of sports and medicine refers to the combination of sports and medicine based on the medical knowledge system in addition to using the principles as well as methods of physical exercise to make exercise more standardized, systematic, and scientific, so as to improve physical quality ${ }^{[1]}$. Under the guidance of medical supervision, exercise plays a role in prevention, treatment, and rehabilitation, so as to achieve the goal of national physical and mental health. It is a new health concept and scientific health behavior. The integration of sports and medicine does not simply overlap the individual functions of sports and medicine, but organically combines the two by integrating sports and medical scientific research technology, medical personnel, material resources, and information resources. This new health concept is applied to jointly promote the physical and mental health of people.

\section{Concept of "integration of sports and medicine"}

The integration of sports and medicine refers to the penetration, supplement, and connection of theoretical ideas and effective practical experience of two disciplines to promote sports by breaking the boundary between sports and medicine. It is a new health service model combined with medical and health departments in physical fitness measurement, health assessment, sports and fitness, preventive treatment, as well as rehabilitative care. Medical staff actively use sports in line with health projects to realize a service model that promotes health. In the process of health intervention, sports practitioners use medical 
knowledge, skills, and equipment for medical supervision to ensure safety and effectiveness. On the other hand, sports and health departments integrate human resources, technology, market, and other resources to apply them into the field of disease prevention, treatment, and rehabilitation, so as to realize the health service model ${ }^{[2]}$. The integration of sports and medicine mainly involves the integration of technology, resources, and other dimensions. In order to realize the service model of prevention, treatment, and rehabilitation, the public practice is explored by using specific, personalized, and targeted exercise programs.

\section{Problems in physical education under the "integration of sports and medicine"}

\subsection{Physical education disciplines with medical characteristics are not highlighted}

Based on the academic foundation of sports science and medicine, the goals in sports include physical health goals, mental health goals, sports participation goals, sports performance goals, and social adaptation goals. The goal of physical education in medical colleges and universities is inseparable from the overall goal of the curriculum, which ultimately prevents students from participating in exercise blindly; rather, it encourages them to rely on medical treatment to cultivate medical and motor skills. According to the development of traditional sports activities, the objectives of physical education curriculum in medical colleges coincide with those of physical education curriculum. Traditional physical education teachers still assume teaching sports skills and improving physical quality among students as the curriculum objectives; they do not emphasize the specificity of physical education curriculum in medical colleges and knowledge still depends on the basic knowledge of scientific principles, exercise methods, and exercise principles ${ }^{[3]}$.

\subsection{Lack of innovative physical education curriculum content}

It is necessary to add health knowledge in physical education, forsake the traditional educational thought with sports technology as the core, establish the concept of "people-oriented" and "health first," as well as promote the integration of sports and medicine. By making full use of the integration of sports and medicine, it is then possible to combine professional advantages with technical knowledge in sports to achieve the ultimate goal. In the current fierce employment environment and complex doctor-patient relationship, only with healthy bodies, excellent psychological qualities, and good interpersonal relationships, medical students, as future personnel of the medical industry, can then meet the social needs and be competent for work. The lack of professional courses related to sports and health shows that the teaching method is still biased toward ordinary universities without any development in project characteristics in combination with medical characteristics. The proportion of theoretical classes is relatively small, whereas the proportion of practical training is relatively large, resulting in an uneven distribution. At the same time, in view of the simple setting of the curriculum goal, students' participation and satisfaction with sports activities are not up to par. In the reform of physical education, it is necessary to enrich the educational content by adding physical education theory courses.

\subsection{Lack of physical education teachers with professional knowledge of conventional medicine}

At present, the teachers are mainly in their 40s, with a wide range of specialty in education. Physical education teachers do not have professional background in sports medicine. There is a shortage of physical education teachers, especially in sports medicine and sports rehabilitation. Moreover, in the process of restructuring and implementing a comprehensive physical education curriculum, medical colleges need more physical education teachers and to constantly update clinical medical knowledge, basic medical knowledge, psychological knowledge, and social knowledge ${ }^{[4]}$. An unscientific method of physical 
education is to remain focused on physical skills and physical activities, which makes it difficult to promote the integration of sports and medicine.

\section{Innovative teaching strategy under the integration of sports and medicine}

\subsection{Strengthening the team of sports medicine teachers}

Relying on the integrated management mechanism, full-time teachers of medicine and sports health in schools should implement a mutual learning strategy. The composition of teachers is the same vertically and horizontally ${ }^{[5]}$. It needs to promote the integration of teachers' profession and doctors' work as well as support each other in professional roles and teaching division. Under the dual guidance of full-time teachers in sports health and rehabilitation department as well as the training of teachers in the infirmary, students need to establish a comprehensive teacher evaluation standard. They complement each other's advantages and jointly lead professional development through professional construction, team building, and talent cultivation. Many teachers have many years of front-line experience in the health and rehabilitation industry, thus having strong teaching and medical support capabilities. Through mutual benefit, full-time teachers can venture in the health rehabilitation industry, carry out on-the-job training, and strengthen the cultivation of practical skills. A joint training mechanism should be established, and regular vocational ability training should be carried out along with professional and technical training, bilateral academic exchanges, and other activities. It is also important to give full consideration to education, carry out practice and scientific research, jointly train full-time teachers, and cultivate professional synchronous skills as well as comprehensive quality.

\subsection{Improving professional skills in education and teaching}

Relying on the training base, schools should actively promote community service as the base to meet the rehabilitation needs of athletes. Relying on the technical advantages of professional teachers in the rehabilitation of sports injuries as well as neck, shoulder, waist, and leg discomfort, it can then strive to provide health rehabilitation services for local communities and surrounding areas on a yearly basis. Teachers' and students' unions should be effectively organized, and the professional knowledge and skills learned should be utilized to provide community services. By actively carrying out community massages, free clinics, and other activities, students' comprehensive quality can be improved, and it encourages students to volunteer in gerocomiums, nursing homes, beauty salons, community centers, and other places. A R\&D Department of Medical Institutions should be established along with an industry-university cooperation management system; schools need to strengthen the cooperation with the medical and sports health industry, rehabilitation treatment, and sports fitness guidance institutions ${ }^{[6]}$. It is necessary to develop and expand cooperation results as well as continue to promote school-enterprise cooperation. Relying on excellent teachers and training base resources can solve the technical problems in the development of sports health and rehabilitation industry, scientific and technological innovation, as well as the service industry. With the integration of sports and medicine, the development of sports health and rehabilitation has brought new opportunities and challenges. By clarifying the training objectives of professional talents, schools can explore the talent training mode, establish the curriculum system, strengthen the training of teachers and the function of the training base, improve students' practical skills and health care abilities, as well as actively find suitable practical abilities.

\subsection{Resetting the traditional teaching objectives in physical education}

The physical education curriculum is the main way to achieve the goal of physical education. The goal of the curriculum is to guide students to achieve the expected learning results through physical education and 
activities. In the context of the integration of sports and medicine, the training objectives of public physical education courses in medical colleges are diversified, focusing on the objectives of traditional courses, such as physical health goals, mental health goals, sports participation goals, sports performance goals, and social adaptation goals. In physical education, it is necessary to increase the theoretical knowledge of medicine and health management as well as sports fitness, cultivate students' awareness of "sports plus medical treatment," as well as understand medical knowledge and skills ${ }^{[7]}$. However, sports, fitness, health care, rehabilitation, and rehabilitative medical courses can cultivate students with comprehensive medical and sports health knowledge and help them to master sports and fitness skills as well as experience sports with their peers.

\subsection{Focusing on improving the comprehensive quality and team building of physical education teachers}

Teachers are the implementers of physical education. Therefore, the integration of physical education and medicine should improve the teaching structure of medical colleges and universities as well as form a reasonable team of teachers. Physical education teachers are not only the implementers of education plans, but also the pioneers of curriculum reform. They are the main promoters of physical education in colleges and universities. The specific measures for the construction of teaching staffs are thereby discussed. Talents in the field of sports medicine should be actively introduced. At present, sports medicine teachers can be introduced on the basis of full-time teachers. The key to cultivating teachers' sports medicine ability is to improve the ability of young teachers. In addition, more opportunities should be provided for young teachers and talents to participate in teaching and scientific research. It is necessary to strengthen and further develop the training for teachers. Under the integration of physical education and medicine, physical education teachers should focus on strengthening the training of basic medical knowledge, sports medicine, and traditional exercise theories ${ }^{[6]}$. It is also necessary to specify the corresponding syllabus and teaching plan, carefully organize the teaching content, and explore the profound training of exercise therapy as well as the knowledge about rehabilitation embedded in the interdisciplinarity of sports medicine. Students should be informed about the happenings and the reasons for them. For students entering physical education institutions, the compulsory course should be an introductory course to understand the integration of sports and medicine ${ }^{[8]}$.

\section{Conclusion}

In conclusion, it is necessary to strengthen the construction of physical education teachers and improve their basic teaching abilities. Physical education courses, offered by physical education teachers in physical education colleges, should be combined with the characteristics of physical education teaching, which should not only meet the outcomes of physical education knowledge, but also cultivate teachers' medical knowledge. Schools should encourage physical education teachers to learn medical knowledge and formulate relevant teacher training plans, so as to ensure a proportional setting of theory to practice in its curriculum. At the same time, it is important to carry out the education on traditional physical health theories and reform the interdisciplinary education of physical education and medicine in medical colleges. The physical education curriculum in medical colleges has important strategic significance. It is a solid foundation and experimental stepping-stone for the early establishment of the talent training mode for the integration of physical education and medicine. In addition, it is also necessary to actively explore the practical path of the integrated education of sports and medicine based on physical education theory courses and characteristic sports courses, so as to provide reference and ideas for the further development of the integrated medical education model. 


\section{Funding}

(1) Shandong Province Social Science Popularization and Application Research Project, "Research on the Construction of 'Hospital + Community + School' Elderly Health Volunteer Service System from the Perspective of Physical and Medical Integration" (Project Number: 2021-SKZC-56).

(2) Tai'an Philosophy and Social Science Research Project, "Research on the Construction of Volunteer Service System of Precision Sports Health Management from the Perspective of Physical and Medical Integration" (Project Number: 2021SKX082).

(3) Research Foundation Project of Taishan University, "Research on the Influence of Fitness Behavior on Health Management of the Elderly in Community from the Perspective of Healthy China" (Project Number: Y-02-2019012).

\section{Disclosure statement}

The authors declare that there is no conflict of interest.

\section{References}

[1] Liu R, Guo Y, 2021, Innovative Exploration on Teaching Mode of Physical Education Health Class in Colleges and Universities under the Background of Physical Education and Medicine Integration. Sichuan Sports Science, 40(04): 117-121. DOI: 10.13932/j.cnki.sctykx.2021.04.26

[2] Zhang A, 2020, Reform of Physical Education in Medical Colleges under the Background of "Integration of Physical Education and Medicine" - A Case Study of Kunming Medical University. Education Forum, 2020(33): 77-80.

[3] Zhang Y, 2021, Exploration on Teaching Reform of Public Physical Education In Medical Colleges and Universities Under the Background of Integration of Physical Education and Medicine. Journal of Wenzhou Medical University, 51(09): 772-775.

[4] Fu C, 2021, Study on Curriculum System of Social Sports Guidance and Management Specialty Under the Background of Sports and Medicine Integration. Research on Innovation of Ice and Snow Sports, 2021(15): 145-146.

[5] Liu Y, 2021, Reflections on the Teaching Reform of the Integration of Sports and Medicine in Medical Colleges and Universities Under the Background of Healthy China. Shanxi Youth, 2021(20): 64-65.

[6] Wang Z, 2021, Research on Physical Education Reform of Traditional Chinese Medicine Colleges and Universities Under the Background of "Combination of Physical Education and Medicine". Scientific and Technology of Stationery and Sporting Goods, 2021(15): 163-164.

[7] Zhang L, Zheng Z, Wu Y, 2021, Teaching Reform of Physical Health Science Course Under the "Integration of Sports and Medicine". Sports Vision, 2021(13): 51-52.

[8] Qin D, 2021 Research on the Development Status and Countermeasures of Sports and Medicine Integration Service Model in China. Shandong Normal University.

\section{Publisher's note}

Bio-Byword Scientific Publishing remains neutral with regard to jurisdictional claims in published maps and institutional affiliations. 